\title{
Perfil sociodemográfico e da violência de alunos da educação básica de escolas do Rio de Janeiro
}

\author{
Sociodemographic and violence profile of students from Rio de Janeiro \\ secondary level schools
}

Marina Maldonado Marins Lopes

Mestre em Educação em Ciências e Saúde Instituto NUTES da Universidade Federal do Rio de Janeiro - NUTES/UFRJ. Rio de Janeiro, RJ - Brasil. marinamaldonadoms@gmail.com

\author{
Maria Pires Domingues Cardoso Guedes \\ Graduanda em Licenciatura em Ciências Biológicas \\ Instituto NUTES da Universidade Federal do Rio de Janeiro - NUTES/UFRJ. \\ Rio de Janeiro, RJ - Brasil. \\ maria.pdcgguedes@gmail.com \\ Sônia Cristina Soares Dias Vermelho \\ Doutora em Educação \\ Instituto NUTES da Universidade Federal do Rio de Janeiro - NUTES/UFRJ. \\ Rio de Janeiro, RJ - Brasil. \\ cristina.vermelho@gmail.com
}

\begin{abstract}
Resumo: O presente trabalho apresenta dados do perfil sociodemográfico e da violência escolar praticada e sofrida por alunos do $9^{\circ}$ an o do Ensino Fundamental de escolas do Rio de Janeiro. O material faz parte de uma pesquisa interinstitucional, que tem como objetivo melhorar a compreensão do fenômeno e auxiliar na busca por estratégias de enfrentamento. Como metodologia, foi realizada uma análise quantitativa e descritiva, através de dad os coletados em questionário do tipo Escala Likert. Os resultados revelam uma maior frequência de sentimentos de felicidade nos agressores, enquanto que, nas vítimas, prevalecem sentimentos ruins, como tristeza e desconsideração. Identificamos, ainda, características dos agressores e vítimas, como popular/forte e impopular/fraco, respectivamente. Por fim, tais resultados apontam o impacto do processo de formação, seja escolar ou familiar (por exemplo, a falta de respeito) sobre a agressividade praticada pelos alunos. Identificamos consequências graves, evidenciando a urgência das políticas de enfrentamento no ambiente escolar.
\end{abstract}

Palavras chave: violência escolar; bullying; adolescentes.

Abstract: This article presents data on the sociodemographic profile and on school violence practiced and suffered by a sample of 9 th grade students from six Rio de Janeiro schools. This work is part of na interinstitutional research aiming to better comprehend the phenomena, and help these arch for confrontation strategies. The methodology consists of conducting a quantitative and descriptive analysis using data collected in a 2019 survey using the Likert Scale Questionnaire. Results revealhig her frequency of feeling of happiness by the aggressors, mean while, the victims had a prevalence of bad feelings, such as sadness and disregard. Further more, we identified the characteristics of the aggressors and victims as being popular/strong, and unpopular/weak, respectively. Lastly, said results indicate the impact of the formative processes, both school and family (for example, lack of respect), on the ag gressiveness carried out by the students. We have identified serious consequences, evidencing the urgency of confrontation policies in the school environment

Key-words: schoolviolence; bullying; adolescentes.

Cite como

(ABNT NBR 6023:2018)

LOPES, Marina Maldonado Marins; GUEDES, Maria Pires Domingues Cardoso; VERMELHO, Sônia Cristina Soares Dias. Perfil sociodemográfico e da violência de alunos da educação básica de escolas do Rio de Janeiro. Dialogia, São Paulo, n. 39, p. 1-20, e20624, set./dez. 2021. Disponível em: https://doi.org/10.5585/39.2021.20624.

American Psychological Association (APA)

Lopes, M. M. M., Guedes, M. P. D. C., \& Vermelho, S. C. S. D. (2021, set./dez.) Perfil sociodemográfico e da violência de alunos da Educação Básica de escolas do Rio de Janeiro. Dialogia, São Paulo, 39, p. 1-20, e20624. https://doi.org/10.5585/39.2021.20624. 
Introdução

O tema a ser tratado neste artigo é a violência, principalmente a que se encontra presente no ambiente escolar. Debatemos, assim, alguns de seus aspectos, suas possíveis causas e consequências no desenvolvimento pessoal e educacional dos indivíduos envolvidos, além das possibilidades para a busca pelo seu enfrentamento.

Dissertar sobre a violência, um problema que sempre acompanhou a história, não é uma tarefa simples. Precisamos debater diversas questões e conceitos que, muitas vezes, divergem. Aqui, definimos esse fenômeno de acordo com a Organização Mundial de Saúde (OMS) (2002), que define a violência como “(...) o uso deliberado de força física ou poder, seja ameaçador ou eficaz, contra si mesmo, outra pessoa, um grupo ou comunidade, que causa ou pode causar ferimentos, morte, dano psicológico, distúrbios do desenvolvimento ou privação".

Monteiro e Saravalli (2015) informam que, no Brasil, a partir da década de 80, houve um aumento significativo nos estudos sobre a temática. Primeiramente, esses estudos focalizavam a análise da criminalidade nas populações marginais. Ao longo do tempo, com a ampliação das discussões sobre os direitos humanos e com o aumento da banalização da violência, houve um interesse maior por pesquisas que buscaram aprofundamento dessa temática. O conceito de violência foi ampliado e passou a estar relacionado aos fatores sociais, como o desemprego, a exclusão social, entre outros.

De acordo com a Organização Mundial de Saúde (OMS) (2002), a violência é um fenômeno onipresente que ameaça a vida, a saúde e a felicidade de todos. Ela está presente em todos os países, desde espaços públicos até os privados, perpassando o seio familiar, nossas ruas, instituições escolares, locais de trabalho, entre outros. Ressalta-se que a sua onipresença, muitas vezes, demonstra a violência como um componente inevitável da condição humana, na medida em que a reação prevalece sobre a prevenção, frequentemente. Portanto, a violência pode ser física ou psicológica, um evento isolado ou contínuo, pode ocorrer entre duas ou mais pessoas ou até com o próprio indivíduo agressor. Ela pode ocorrer em qualquer ambiente, encontrando-se nas mais importantes instituições socializadoras, como a família, a escola e o bairro (MALTA et al., 2017).

Também concordamos com Silva e Salles (2010, p. 218) ao especificarem a violência como “(...) o desrespeito, a negação do outro, a violação dos direitos humanos que se soma à miséria, à exclusão, à corrupção, ao desemprego, à concentração de renda, ao autoritarismo e às desigualdades presentes na sociedade brasileira". Desta forma, torna-se essencial discutir sobre a violência entendendo-a como fruto de uma sociedade competitiva e desigual, como "Uma sociedade gestada 
no individualismo, movida pelo consumo e estruturada pela lógica da competição e do sucesso" (CORRÊA, 2017, p. 15).

Neste âmbito, há conflitos de interesses, lutas de classes, problemas psicológicos, desestruturação familiar, falta de investimento na educação, entre outros fatores culturais e históricos que interferem diretamente e indiretamente no contexto da violência escolar. Concordamos com Corrêa (2017), quando afirma que "um modelo de sociedade que prioriza a competição é pouco propício às formas de convivência, tais como as que se baseiam na amizade, no respeito e na solidariedade" (p. 92).

Cotidianamente, vemos, falamos e reproduzimos violência. Ela se torna presente de forma global e local, em diversos meios sociais: na rua, na casa ao lado, no trabalho, nas escolas e, diariamente, nos noticiários midiáticos. Acabamos, muitas vezes, tomando como normal algumas formas de violência e cabe a nós refletir sobre como agimos conosco, com o outro. Contudo, esse pensamento vem sofrendo avanços significativos e o objetivo de combater as raízes da violência torna-se cada vez mais emergencial.

Além de repensarmos nossa sociedade, é imprescindível compreendermos melhor o fenômeno para que as prevenções ocorram. Essa importância levou a OMS a criar uma classificação da violência explicitada no "Relatório Mundial sobre violência e saúde", a qual foi dividida em três categorias: violência dirigida contra si mesmo (exemplo do suicídio ou automutilação), violência interpessoal (exemplo de violência familiar, parceiros ou comunidade) e violência coletiva, que pode ser ordem social, política ou econômica (exemplo do terrorismo e conflitos armados). Desta forma, é importante ressaltar que trataremos, aqui, especificamente, sobre a violência interpessoal vivenciada na escola.

Esse ambiente é mais um meio social que não se exclui desse fenômeno. Quantas vezes ouvimos falar sobre violência entre alunos, entre professores/gestores e alunos, entre familiares e alunos/professores/gestores? Quantas vezes ouvimos relatos de professores, gestores e alunos com problemas psicológicos devido a diversas agressões que sofreram nesse ambiente e até em outros? Crochick (et al. ,2014) mencionam alguns dos problemas presentes na escola contemporânea, como: as dificuldades de aprendizagem, a indisciplina, a discriminação, os problemas de relacionamentos entre pares e entre o corpo docente e discente, além do Bullying.

A escola, como outros diversos espaços, é um ambiente de construção social onde todos os indivíduos estão em constante transformação. Professores, alunos, família e todos os funcionários da escola fazem parte da sociedade, como os sujeitos de outros ambientes também. Eles apresentam diferentes valores, culturas, conflitos, tensões, desejos, interesses e reproduzem 
os valores construídos socialmente. Estes são, muitas vezes, valores voltados para a competição e individualidade do ser. Mas cabe a cada um de nós refletir sobre como podemos construir uma sociedade que estimule valores de amorosidade, empatia, respeito, solidariedade, equidade, entre outros. Logo, acreditamos que a escola pode ser um dos ambientes ideais para estimular essa reflexão e esse olhar mais coletivo.

Para nós, é importante refletir acerca da complexidade da violência, principalmente a vivenciada no âmbito escolar. É imprescindível entender que esse fenômeno é um reflexo do que vivemos em nosso passado e presente, mas que isso não quer dizer que determinará o que viveremos em nosso futuro. Acreditamos que, juntos, temos a capacidade de alterar a nossa realidade.

Dessa forma, a violência que se manifesta na escola é considerada "violência escolar", apontada como um obstáculo à aprendizagem (CROCHIK; CROCHIK, 2017a) e ao desenvolvimento desses indivíduos (MALTA et al., 2017). A violência escolar pode afetar a interação social dos alunos, seu desempenho acadêmico, além de trazer consequências psíquicas graves aos sujeitos envolvidos “(...) desde uma angústia acentuada até o assassinato e suicídio” (CROCHIK; CROCHIK, 2017a, p.22), constituindo um grave problema de saúde pública (MALTA et al., 2017).

Porém, existe uma grande dificuldade na identificação da agressão Pelo fato de, muitas vezes, ela acontecer de forma velada, podendo ser confundida com "brincadeiras" (OLIVEIRA et al., 2018). Silva (et al., 2018) dizem que, devido aos altos índices de violência escolar, essa temática percorre o mundo, passando, também, a ser estudada por meio da faceta denominada Bullying. Contudo, existem muitos outros tipos de violência na escola e que também não podem deixar de ser analisados, como o preconceito, a exclusão, o autoritarismo, o suicídio, o abuso sexual, desrespeito, etc. Ou seja, é algo que ocorre não apenas entre alunos, mas entre todos os sujeitos pertencentes a este ambiente.

Nesse contexto, Leon e Nicole Crochick (2017a) abrangem os conceitos de hierarquia oficial e não oficial no âmbito escolar. A oficial está ligada ao desempenho acadêmico; já a não oficial está ligada aos esportes, popularidade, namoro e brigas. Em suas pesquisas, os autores descobriram que, no ambiente escolar, alunos com um bom desempenho na hierarquia não oficial e/ou desempenho ruim na hierarquia oficial tendem a praticar mais violência. Já os alunos que não se destacam em nenhuma das duas hierarquias tendem a ser vítimas da violência.

O Bullying é definido por estes autores como agressões entre pares, sendo verbais ou físicas, diretas ou indiretas que um aluno ou um grupo de alunos exerce (ou exercem), por um longo 
período de tempo, sobre vítimas que apresentam alguma fragilidade. A forma direta pode ser por meio de agressões físicas e comentários ofensivos, enquanto a indireta pode ser por meio de descaso, boatos e calúnia. Mas é importante ressaltar que a dinâmica do Bullying se estende para além dos alunos e inclui os demais colegas, professores, a comunidade escolar e a família (OLIVEIRA et al., 2017; MALTA et al., 2017).

Dessa forma, faz-se necessário entender sobre as formas de envolvimento dos estudantes, quanto às suas atitudes diante do fenômeno Bullying. De acordo com Neto (2005), podemos dividir os sujeitos em: vítimas, agressores e testemunhas. Nessa mesma linha de pensamento, autores como Leon Crochick e Nicole Crochick (2017a); e Corrêa (2017) salientam que, na prática do Bullying, além da vítima e do agressor, pode existir o observador passivo ou espectador.

Em se tratando exclusivamente das vítimas, o mesmo autor informa que “(...) algumas características físicas, comportamentais ou emocionais podem torná-lo mais vulnerável às ações dos autores e dificultar a sua aceitação pelo grupo” (p. 167). Menciona-se, também, que esses alunos são expostos às ações que os causem danos, de forma repetida e durante algum tempo, podendo apresentar e agravar sentimentos de “(...) medo, a tensão e a preocupação com sua imagem podem comprometer o desenvolvimento acadêmico, além de aumentar a ansiedade, insegurança e o conceito negativo de si mesmo. Pode evitar a escola e o convívio social, prevenindo-se contra novas agressões" (p. 167).

Com relação aos impactos que essa violência exerce na saúde física e mental dos estudantes, Silva (et al., 2017), Alcantara (et al.,2019) e Oliveira (et al., 2017) citaram: ansiedade, baixa autoestima, depressão, automutilação, solidão e tendência ao suicídio. Além destes, comportamentos como delinqüência e uso de drogas também estão associados.

Além disso, Corrêa (2017) acrescenta que, em decorrência da complexidade de comportamentos e reações, as vítimas podem ser de três formas: as típicas, as provocadoras e as agressoras. O primeiro tipo refere-se àquelas crianças e jovens mais ansiosos, inseguros e/ou com um aspecto físico que possa identificar uma fragilidade ao seu agressor. A segunda classificação de vítima fica restrita a um grupo menor, caracterizado por aquelas que tentam se defender quando são atacadas ou insultadas, mas não são bem sucedidas em suas tentativas. Por fim, a terceira forma é caracterizada por vítimas que cometem agressões com os outros como forma de compensar o seu sofrimento, gerando um ciclo vicioso de violência, contribuindo para aumentar os casos de Bullying.

Ainda em relação às vítimas na prática de Bullying, Oliveira e Barbosa (2012) indicam estudos (Carter \& Spencer, 2006; Flynt \& Morton, 2007; B. O. Pereira, 2008; Smith, 2002), que 
afirmam que existe uma maior chance de isso ocorrer entre crianças e adolescentes com deficiência, dificuldades de aprendizagem e dotação de talento, pois esses indivíduos tendem a apresentar “(...) menor repertório de competências sociais e com poucas relações de amizade, tendo maiores chances de serem rejeitados" (p.748).

Além das vítimas, muitos autores da agressão apresentam características específicas, como a dificuldade de resolver conflitos e a agressividade com os seus colegas de turma, professores, funcionários da escola e até mesmo com os seus pais. Mas também podem ser considerados como populares pelos colegas de classe, como mencionado por Neto (2005):

O autor de bullying é tipicamente popular; tende a envolver-se em uma variedade de comportamentos anti sociais; pode mostrar-se agressivo inclusive com os adultos; é impulsivo; vê sua agressividade como qualidade; tem opiniões positivas sobre si mesmo; é geralmente mais forte que seu alvo; sente prazer e satisfação em dominar, controlar e causar danos e sofrimentos a outros. Além disso, pode existir um componente benefício em sua conduta, como ganhos sociais e materiais. São menos satisfeitos com a escola e a família, mais propensos ao absenteísmo e à evasão escolar e têm uma tendência maior para apresentarem comportamentos de risco. (p. 167).

Através das narrativas de adolescentes sobre experiências e situações de Bullying que eles vivenciam no ambiente escolar, Oliveira et al. (2018, p. 754), identificaram, em suas pesquisas, quais foram as condições específicas para impulsionar as ações de Bullying. Dessa forma, as motivações da agressão indicadas pelos jovens foram: a inveja; a intolerância à diversidade; desequilíbrio de poder entre os sujeitos, "consequente da diferença de idade, tamanho, desenvolvimento físico ou emocional, ou do maior apoio dos demais estudantes" (NETO, 2005, p.165); questões subjetivas dos agressores; desejo de causar sofrimento e características das vítimas que as diferem do grupo de pares.

Já com relação às testemunhas, Neto (2005) menciona que “(...) a maioria dos alunos não se envolve diretamente em atos de bullying e geralmente se cala por medo de ser a próxima vítima, por não saberem como agir e por descrerem nas atitudes da escola" (p. 167). Contudo, muitos jovens também acabam acreditando que esses comportamentos agressivos podem ser um bom caminho para alcançar a popularidade e o poder, se tornando autores de Bullying. Outros podem aderir a práticas violentas por pressão dos colegas ou podem tornar-se alvos também. Logo, as testemunhas estão sujeitas a sofrerem dos mesmos problemas que as vítimas ou de desenvolverem comportamentos como os dos agressores (OLIVEIRA et al., 2017). 
Leon Crochick e Nicole Crochick (2017a); e Corrêa (2017) também discutem essa questão, salientando que o observador passivo ou espectador é aquele que não pratica o ato, mas também não faz nada para cessá-lo, seja por satisfação, por medo ou até mesmo por impotência.

Oliveira et al. (2018), ao entrevistarem jovens estudantes, também observaram, em suas narrativas, que, muitas vezes, eles não intervêm nas situações de Bullying com receio de serem agredidos, por não visualizarem melhor, por se sentirem sozinhos, por não conhecerem as vítimas ou porque, na opinião deles, estas apresentam características que justificam as agressões. Mas com relação aos estudantes que interferiram nas agressões, mencionam ter essa relação “(...) por se colocar no lugar do outro, por julgarem incorreto o uso da violência, por serem colegas das vítimas ou porque tinham casos na família de pessoas que sofreram preconceito ou discriminação" (p. 754).

Com relação às condições que podem favorecer o surgimento da violência escolar, em específico do Bullying, seja com relação aos praticantes ou as vítimas, citamos aspectos do contexto familiar, características sociodemográficas e características individuais. Giordano e Nazareth (2017), ao entrevistarem docentes, mencionam que a violência presente na comunidade, a ausência de afeto e também a violência doméstica podem contribuir para a criação de crianças mais agressivas.

Desta forma, entendemos que esses comportamentos devem ser combatidos não só pelas escolas, como também pela família e por toda a sociedade que enseja esse fenômeno, assim como o estudo de Malta et al. (2017) que demonstra a necessidade de mobilizar toda a sociedade na perspectiva do seu enfrentamento. Entretanto, a violência, segundo Oliveira et al. (2018) tem sido naturalizada e utilizada como estratégia para a resolução de conflitos.

A partir disso, este artigo busca apresentar os dados do perfil sociodemográfico e de violência praticada e sofrida por alunos do $9^{\circ}$ ano do Ensino Fundamental de seis escolas do Rio de Janeiro. Entendemos que a violência afeta a vida de toda a comunidade escolar e acreditamos que este espaço social é de extrema importância na constituição dos indivíduos e no enfrentamento à violência. Para nós, uma das prioridades da educação deve ser a afirmação da igualdade de direitos e deveres de todos os cidadãos, independente de sexo, gênero, cor, orientação sexual, crença ou situação econômica.

\section{Metodologia}

Cabe ressaltar que os dados aqui apresentados fazem parte de uma pesquisa interinstitucional, nomeada "Violência escolar: discriminação, bullying e responsabilidade”, que visa a identificar aspectos ligados aos praticantes e vítimas da violência escolar, especificamente do 
bullying, com objetivo de buscar estratégias para seu enfrentamento. Essa pesquisa mais ampla contempla a área de cidadania, violência e direitos humanos e foi composta por 16 instituições: 4 internacionais, sendo essas a Espanha, Argentina, Portugal e México; e 12 nacionais, incluindo a cidade do Rio de Janeiro, na qual fomos as responsáveis pela pesquisa.

Para tal, salienta-se que a presente pesquisa é de caráter quantitativo e descritivo. Foi realizada no ano de 2019, tendo como instrumento de coleta questionários do tipo Escala Likert. Os sujeitos da pesquisa foram 225 alunos do $9^{\circ}$ ano do Ensino Fundamental de 6 escolas do Rio de Janeiro. Essa amostra foi definida através de três questões: primeiramente, buscamos por uma variedade de instituições, abrangendo escolas particulares e públicas, sendo estas federais e municipais. O segundo critério para essa escolha foi o interesse das escolas e facilidade quanto à autorização para a realização da pesquisa, uma vez que o cenário mostrou-se extremamente burocrático, o que atrasaria a coleta dos dados. Por fim, não menos importante, foi o critério da região dessas escolas na cidade do Rio de Janeiro, pois buscamos por locais de melhor acesso para as pesquisadoras.

Com o objetivo de preservar a identidade das escolas pesquisadas, assim como para uma melhor organização e compreensão, criamos um quadro com os códigos que usaremos para mencioná-las neste artigo. Segue quadro abaixo:

Quadro 1- Escolas participantes da pesquisa e suas localidades

\begin{tabular}{|c|c|c|}
\hline $\begin{array}{c}\text { Código das } \\
\text { Escolas }\end{array}$ & $\begin{array}{c}\text { Bairros do Rio de } \\
\text { Janeiro }\end{array}$ & Tipo de Instituição \\
\hline CAL & $\begin{array}{c}\text { Lagoa Rodrigo de } \\
\text { Freitas }\end{array}$ & Escola Pública Federal \\
\hline CPS & São Cristóvão & Escola Pública Federal \\
\hline CPT & Tijuca & Escola Pública Federal \\
\hline COB & $\begin{array}{c}\text { Bancários - Ilha do } \\
\text { Governador }\end{array}$ & Escola Pública Municipal \\
\hline CPM & $\begin{array}{c}\text { Moneró - Ilha do } \\
\text { Governador }\end{array}$ & Escola Particular \\
\hline CRF & $\begin{array}{c}\text { Freguesia - Ilha do } \\
\text { Governador }\end{array}$ & Escola Pública Municipal \\
\hline
\end{tabular}

Source: 
Entre as seis escolas pesquisadas, cinco eram públicas e uma particular. Das públicas, três eram federais e duas municipais. As escolas federais tinham grande número de alunos, muitas turmas de $9^{\circ}$ ano, ótima infraestrutura e apoio pedagógico. As escolas municipais possuíam menor número de alunos, somente duas turmas de $9^{\circ}$ ano, precário investimento para questões de infraestrutura e apoio pedagógico. Já a escola particular era pequena, contendo somente uma turma de $9^{\circ}$ ano, com apenas nove alunos, porém possuía uma boa infraestrutura e apoio pedagógico.

Para realização da coleta de dados, dividimos a parte metodológica em algumas etapas. Primeiramente, realizamos reuniões para convite e apresentação da pesquisa para os gestores. Após o aceite para participação, houve aplicação de questionário com os coordenadores para entender melhor sobre a estrutura das instituições. É importante deixar claro que a primeira etapa faz parte do projeto mais amplo, mas foi de grande valor para conhecermos as escolas e os profissionais que nela atuam.

$\mathrm{Na}$ segunda etapa, houve uma breve apresentação da pesquisa para os alunos, na qual foram explicadas todas as dúvidas que os sujeitos tiveram. Após essa conversa inicial, ocorreu a entrega do Termo de Consentimento Livre e Esclarecido (TCLE) para os alunos interessados em participar da pesquisa. Era preciso que eles entregassem aos seus responsáveis para estes últimos autorizassem a sua participação no estudo.

Além disso, cabe mencionar que essa pesquisa teve aprovação do Comitê de Ética em Pesquisa da Universidade de São Paulo, sob o parecer $\mathrm{n}^{\circ}$ 1.218.644, de forma que os procedimentos éticos fossem garantidos. Dessa forma, os questionários foram realizados em locais que asseguraram a privacidade dos participantes e conduzidos somente após a assinatura dos termos pelos responsáveis dos sujeitos menores de idade, que receberam previamente todas as informações sobre a pesquisa, cientificando sobre a metodologia da qual seus filhos participariam. Também foi garantida a voluntariedade da participação nesta pesquisa, o sigilo das informações pessoais e a possibilidade de desistência a qualquer momento. Por fim, todos os participantes foram informados previamente que os dados serão utilizados para futuras publicações.

A aplicação dos questionários sobre a violência escolar foi combinada com alguns professores que disponibilizaram o tempo de sua aula em cada turma do nono ano. Essa aplicação ocorreu de forma individual. Porém, na sala de aula com todos os outros participantes. Para que um participante não influenciasse na resposta do outro, dispomos os alunos afastados uns dos outros. Além deles, contamos com a presença do professor responsável e das pesquisadoras, as quais estavam disponíveis para eventuais dúvidas. A atividade teve uma duração máxima de 
sessenta minutos em cada turma. No entanto, disponibilizamos tempo extra para aqueles alunos que não terminavam dentro do prazo estipulado por nós.

Após os questionários serem respondidos, as informações coletadas foram organizadas e computadas em tabelas do Excelpara a realização da análise quantitativa dos dados, obtendo, assim, a frequência e porcentagem das categorias presentes no questionário dos alunos.

Como já mencionamos, esse artigo faz parte de uma pesquisa mais ampla. Sendo assim, cabe ressaltar que, além deste artigo, futuras análises estão sendo realizadas para complementar os dados dessa pesquisa.

\section{Resultados}

No tocante à apresentação dos dados coletados neste trabalho, foram criadas seis tabelas, são elas: tabela 1, que apresenta a quantidade de sujeitos participantes por escola; tabela 2, que apresenta os dados do perfil sociodemográfico dos participantes desta pesquisa, incluindo perguntas discursivas sobre questões de gênero, religião, tipo de deficiência, questões raciais e uma pergunta múltipla escolha com relação ao nível socioeconômico deles.

Já as três seguintes tabelas apresentam os dados do perfil da violência e do bullying, são elas: tabela 3, que apresenta o sentimento dos praticantes ao realizarem a agressão; tabela 4, que apresenta o sentimento dos alvos ao sofrerem a agressão; tabela 5, que apresenta quais são os motivos que levam à agressão e tabela 6 , que apresenta quais são as características dos autores e alvos da agressão. Todas essas perguntas foram múltiplas escolhas, mas com a opção de incluir outras questões que os sujeitos achassem relevantes para a pesquisa. Agora, passamos para o detalhamento de cada uma delas.

\section{Perfil da amostra}

Os dados apresentados a seguir mostram os resultados do perfil da amostra, contendo a frequência e porcentagem de cada item, a partir dos questionários realizados com os estudantes do $9^{\circ}$ ano do ensino fundamental de escolas do Rio de Janeiro.

Como já mencionado, a tabela 1 refere-se à frequência e porcentagem com relação à participação dos sujeitos pesquisados em cada escola. Na primeira coluna encontram-se os códigos das escolas. Na segunda coluna é possível observar a frequência dos participantes na pesquisa. $\mathrm{Na}$ terceira coluna verifica-se a porcentagem da participação desses sujeitos comparadas entre as escolas; na quarta, apresentamos o total de alunos do $9^{\circ}$ ano do Ensino Fundamental em cada 
escola e a quinta coluna é a porcentagem de alunos participantes de acordo com o total de alunos naquela escola. Segue tabela abaixo:

Tabela 1 - Quantidade dos sujeitos participantes em cada escola

\begin{tabular}{|l|l|l|l|l|}
\hline $\begin{array}{l}\text { Código das } \\
\text { escolaspesquisa } \\
\text { das no Rio de } \\
\text { Janeiro }\end{array}$ & $\begin{array}{l}\text { Frequência de } \\
\text { participantesdo } \\
\text { ano do Ensino } \\
\text { Fundamental }\end{array}$ & $\begin{array}{l}\text { \% de } \\
\text { participantes } \\
\text { comparados entre } \\
\text { escolas } \\
\text { pesquisadas }\end{array}$ & $\begin{array}{l}\text { Total de alunos no } \\
9^{\circ} \text { ano do Ensino } \\
\text { Fundamental em } \\
\text { cada escola } \\
\text { pesquisada }\end{array}$ & $\begin{array}{l}\text { \% da participação } \\
\text { de acordo com o } \\
\text { total de alunos do } \\
\mathbf{9}^{\mathbf{o}} \text { ano do Ensino } \\
\text { Fundamental }\end{array}$ \\
\hline CAL & 23 & $10,2 \%$ & 50 & $46 \%$ \\
CPS & 35 & $15,6 \%$ & 240 & $14,6 \%$ \\
COB & 67 & $31,6 \%$ & 120 & $59,1 \%$ \\
CPM & 8 & $29,8 \%$ & 96 & $69,8 \%$ \\
CRF & 21 & $3,6 \%$ & 80 & $88,8 \%$ \\
\hline
\end{tabular}

Source:

Sendo assim, foi possível observar que a escola que obteve maior frequência de participação, quando comparada com as outras escolas, foi a escola C, com 31,6\%, sendo essa da rede Federal e a escola D, com 29,8\%, sendo essa da rede Municipal. Essas escolas foram umas das que apresentaram um grande número de discentes matriculados no $9^{\circ}$ ano do Ensino Fundamental. Contudo, a escola B, uma escola pública federal, por mais que tenha apresentado um maior número de alunos matriculados, total de 240 alunos, não foi a que apresentou uma maior frequência na pesquisa, com apenas 15,6\%, quando comparada com as outras escolas, já que apresentou baixa frequência de participação, com 14,6\%.

Além disso, cabe ressaltar que a escola E, quando comparada com as outras escolas, teve uma frequência baixa, de apenas 3,6\%, mas é uma escola pequena, com apenas uma turma de $9^{\circ}$ ano e um total de nove alunos. Sendo assim, observamos que $88,8 \%$ dos seus alunos se dispuseram a participar da pesquisa. 
Já na tabela 2, é possível observar o perfil sociodemográfico dos sujeitos pesquisados. $\mathrm{Na}$ primeira coluna nomeamos as características sociodemográficas que julgamos relevantes para avaliar (questões de gênero, raça, religião, deficiência e nível sócioeconômico). Na segunda coluna encontra-se a frequência e na terceira coluna a porcentagem dessas mesmas características. Com relação ao nível socioeconômico (NSE), nos baseamos no Critério de Classificação Econômica Brasil de 2019. Dividimos em quatro colunas: na primeira coluna apresentamos a pontuação dos alunos de acordo com as respostas no questionário; na segunda coluna apresentamos as classes de acordo com o Critério Brasil,e na terceira e quarta colunas estão a frequência e porcentagem, respectivamente. Segue tabela abaixo:

Tabela 2 - Perfil sociodemográfico dos sujeitos

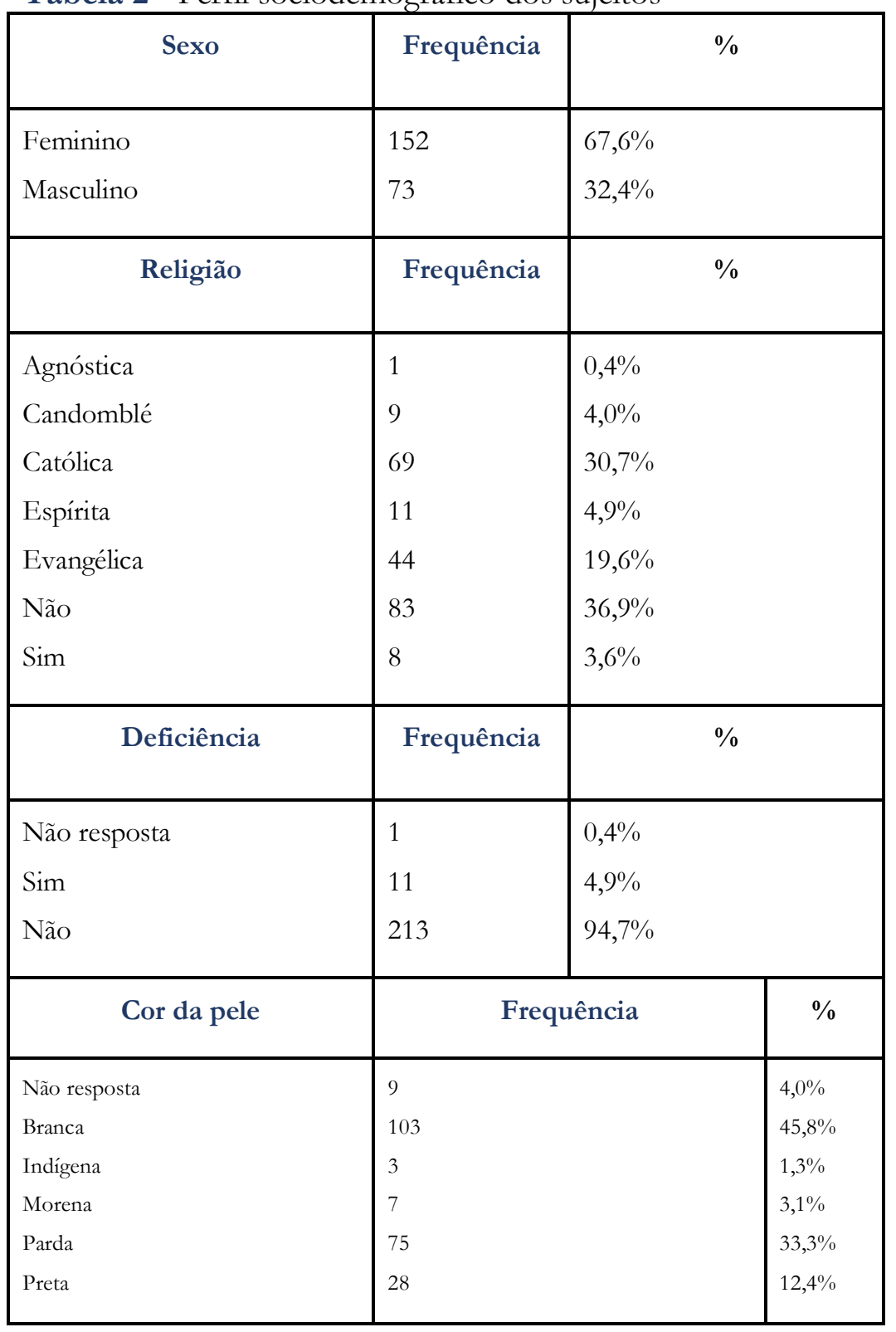




\begin{tabular}{|l|l|l|l|}
\hline \multicolumn{1}{|c|}{ Nível Sócio Econômico } & \multicolumn{1}{|c|}{ Classe } & Frequência & \% \\
\hline Não resposta & & 1 & $0,4 \%$ \\
Menos de 16 & D/E & 7 & $3,1 \%$ \\
De 16 a 22 & C2 & 27 & $12,0 \%$ \\
De 22 a 28 & C1 & 54 & $24,0 \%$ \\
De 28 a 37 & B2 & 68 & $30,2 \%$ \\
De 37 a 44 & B1 & 35 & $15,6 \%$ \\
De 44 a 100 & A & 33 & $14,7 \%$ \\
TOTAL & & 225 & $100 \%$ \\
\hline
\end{tabular}

Source:

Desta forma, é possível observar, na tabela 2, que o sexo que prevaleceu na pesquisa foi o feminino, com 67,6\%. Quanto à religião, 30,7\% dos alunos se autodeclararam católicos; porém, $36,9 \%$ da amostra identificou não possuir nenhuma crença. Com relação à presença ou não de alguma deficiência, somente $4,9 \%$ dos alunos identificaram ter deficiência, sendo apenas 11 dos 225 sujeitos participantes. Com relação à cor da pele, a que obteve maior frequência foi a cor branca, com 45,8\%, seguida da cor parda, com 33,3\%. Já com relação aos níveis socioeconômicos, os que prevaleceram foram $\mathrm{B} 2$ e $\mathrm{C} 1$, com $30,2 \%$ e $24,0 \%$, respectivamente.

\section{Perfil da violência e do bullying}

Com relação ao perfil de violência e bullying, as seguintes tabelas apresentam o que os alunos pensam sobre violência e bullying, quanto ao sentimento dos agressores e vítimas, os motivos das causas de agressões, além das características dos autores da agressão e característica dos alvos.

As tabelas 3 e 4 apresentam a frequência e porcentagem dos sentimentos dos autores e alvos da agressão, respectivamente. $\mathrm{Na}$ primeira coluna, podemos observar os sentimentos dos autores e alvos da agressão. Na segunda coluna, a frequência com que esses sentimentos foram escolhidos pelos participantes e, na terceira coluna, a porcentagem com a qual cada um desses sentimentos apareceu em nossa pesquisa. Cabe ressaltar que os alunos poderiam sugerir outros sentimentos além dos listados por nós. Seguem tabelas abaixo: 
Tabela 3 - Frequência e porcentagem do que sentiram os autores da agressão

\begin{tabular}{|l|l|l|}
\hline Como se sentiu o autor da agressão & Frequência & $\%$ \\
\hline Feliz & 37 & 27 \\
\hline Covarde & 24 & 18 \\
\hline Odiado & 19 & 14 \\
\hline Não perdedor & 19 & 14 \\
\hline Corajoso & 15 & 11 \\
\hline Popular & 9 & 7 \\
\hline Vencedor & 8 & 6 \\
\hline Melhor & 4 & 3 \\
\hline
\end{tabular}

Source:

Tabela 4 - Frequência e porcentagem de como se sentiram os alvos da agressão

\begin{tabular}{|l|l|l|}
\hline Como se sentiu o alvo da agressão & Frequência & $\%$ \\
\hline Tristeza & 67 & 18 \\
\hline Desconsiderado & 54 & 15 \\
\hline Inferioridade & 53 & 15 \\
\hline Ódio & 52 & 14 \\
\hline Pior & 35 & 10 \\
\hline Impotência & 30 & 8 \\
\hline Medo & 26 & 7 \\
\hline Vingança & 26 & 7 \\
\hline Perdedor & 20 & 6 \\
\hline
\end{tabular}

Source:

Desta forma, podemos observar, na tabela 3, que, quanto ao sentimento dos agressores, $27 \%$ dos alunos responderam o sentimento "feliz" como sendo o sentimento que prevalece nos agressores ao praticarem atitudes violentas. Porém, 18\% se sentiu "covarde", e 14\% "odiado" e 
"não perdedor". Já na tabela 4, quanto aos sentimentos dos alvos da agressão, aparecem sentimentos mais negativos, sendo 18\% "tristeza", 15\% "desconsideração" e "inferioridade", e 14\% “ódio”.

A tabela 5 apresenta o resultado do que os alunos consideram ser os motivos para alguém praticar a violência. Dessa forma, a primeira coluna se refere aos motivos para agressão; a segunda coluna apresenta a frequência com a qual esses motivos apareceram na pesquisa e a terceira coluna é a porcentagem desses dados. Cabe ressaltar que os alunos poderiam sugerir outros motivos além dos listados por nós. Segue tabela abaixo:

Tabela 5 - Frequência e porcentagem dos motivos que levam a agressão

\begin{tabular}{|l|l|l|}
\hline Motivos para agressão & Frequência & $\%$ \\
\hline Falta de respeito & 103 & 16 \\
\hline Não tem o que fazer & 97 & 15 \\
\hline Sem limites & 94 & 15 \\
\hline Carência & 67 & 10 \\
\hline Preconceito & 53 & 8 \\
\hline Não tem atenção & 51 & 8 \\
\hline Revidar & 46 & 7 \\
\hline Diferentes & 45 & 7 \\
\hline Não se defende & 35 & 5 \\
\hline Não se enturma & 21 & 100 \\
\hline Apanham & 639 & 3 \\
\hline Total & & \\
\hline
\end{tabular}

Source:

Com relação à tabela 5 , sobre os motivos que levam à agressão, os elementos que tiveram maior frequência foram a "falta de respeito" com 16\%, "não tem o que fazer" e "ser sem limites" com $15 \%$ das escolhas. Cabe ressaltar que o número total foi superior ao número de participantes, pois eles podiam escolher mais de uma opção. 
Por fim, não menos importante, a tabela 6 possui os dados das características dos autores e dos alvos da agressão, sendo todas essas as opiniões pessoais dos alunos que responderam ao questionário. Na primeira coluna, trazemos algumas características que podem estar ligadas tanto aos autores (segunda coluna), como aos alvos (terceira coluna). Apresentamos, também, a frequência e porcentagem de cada uma dessas características, com relação aos autores e alvos da agressão. Segue tabela abaixo:

Tabela 6 - Frequência e porcentagem das características dos autores e alvos da agressão

\begin{tabular}{|c|c|c|c|c|}
\hline Características & \multicolumn{2}{|c|}{ Autor } & \multicolumn{2}{|c|}{ Alvo } \\
\hline - & Frequência & $\%$ & Frequência & $\%$ \\
\hline Impopular & 29 & 13,6 & 135 & 63,1 \\
\hline Fraco(a) & 27 & 12,6 & 133 & 62,1 \\
\hline Mau/má esportiva & 50 & 23,4 & 111 & 51,9 \\
\hline Gordo(a) & 36 & 16,8 & 120 & 56,1 \\
\hline Usa óculos & 51 & 23,8 & 114 & 53,3 \\
\hline Magro(a) & 114 & 53,3 & 98 & 45,8 \\
\hline Afeminado/Masculinizada & 40 & 18,7 & 105 & 49,1 \\
\hline Boas notas & 78 & 36,4 & 103 & 48,1 \\
\hline Más notas & 122 & 57 & 81 & 37,9 \\
\hline Com deficiência & 6 & 2,8 & 90 & 42,1 \\
\hline Negro(a) & 45 & 21 & 75 & 35 \\
\hline Bom/boa esportista & 119 & 55,6 & 51 & 23,8 \\
\hline Popular & 146 & 68,2 & 34 & 15,9 \\
\hline Forte & 136 & 63,6 & 28 & 13,1 \\
\hline
\end{tabular}

Source: 
Desta forma, na tabela 6, ficam em evidência na categoria "autor" da agressão as características como: popular com 68,2\% e forte com 63,6\%. Quanto aos "alvos" da agressão, as características com maior frequência foram: impopular, com 63,1\% e fraco, com 62,1\%.

\section{Discussão}

Através dos resultados obtidos quanto à frequência na participação dos alunos observados na tabela 1, torna-se importante ressaltar a dificuldade que tivemos para alcançar a amostra necessária para a pesquisa. $\mathrm{Na}$ escola $\mathrm{B}$, com 240 alunos no $9^{\circ}$ ano, somente 35 se interessaram em participar da pesquisa. Da mesma forma, na escola F, de 80 alunos, somente 26 foram pesquisados. Nota-se que, apesar da relevância do tema da pesquisa, ele pode trazer sensações desconfortáveis aos sujeitos, sendo esses jovens entre 14 e 16 anos, bem como seus responsáveis. Por outro lado, conseguimos uma frequência maior em outras escolas, como a escola $C$, em que mais da metade de seus alunos participaram: de um total de 120 alunos, 71 participaram, ou seja, 59,1\% de frequência e a escola E, na qual 8 dos 9 alunos participaram, com um total de 88,8\% de participação.

Com relação ao perfil sociodemográfico dos alunos, presente na tabela 2 , houve um maior interesse de participação por parte do sexo feminino. De acordo com o estudo de Malta et al. (2017) adolescentes do sexo masculino estão mais envolvidos em situação de violência nas vias públicas, podendo explicar a falta de interesse e/ou receio do tema por parte desses alunos em serem pesquisados. Entendemos que o estudo sobre assuntos como esses tem suas limitações. Sendo assim, acreditamos ser necessário repensar de que forma podemos alcançar tanto vítimas quanto agressores para que haja uma melhor compreensão do tema e busca pelo seu enfrentamento.

Quanto ao nível socioeconômico (NSE), obteve-se um resultado entre as classes B2 e C1, sendo essas consideradas classes médias, mas também se obteve uma frequência de classes altas e baixas. É interessante ressaltar que essa diversidade socioeconômica pode ser explicada pela forma de ingresso dos alunos, por meio de Sorteio Público de vagas ou Processo de Seleção e Classificação de candidatos através de provas de Matemática, de Português e Redação, para o $6^{\circ}$ ano do Ensino Fundamental de metade das escolas pesquisadas.

É evidente como a violência escolar afeta os sujeitos que estão envolvidos, sejam eles vítimas ou agressores. Os sentimentos negativos que apareceram nos alvos da agressão, contidos na tabela 3, são preocupantes para a integridade física e mental dos indivíduos. A violência pode gerar consequências psíquicas graves, e "as vítimas [...] podem sofrer de problemas de relacionamentos e de internalização relacionados à ansiedade, depressão e baixa autoestima" (OLIVEIRA et al.2018). Os sentimentos e sinais revelados pelos sujeitos não podem ser ignorados, 
tampouco menosprezados, pois “(...) ninguém será capaz de se colocar no lugar do outro para, efetivamente, descrever a intensidade e a dimensão de sua dor" (CORREA, 2017, p. 91)

Quanto aos agressores, é importante ressaltar como os aspectos de formação e educação são bastante indicados pelos alunos na tabela 4. Entende-se, dessa forma, que o contexto familiar e social em que o indivíduo vive pode afetar na construção da sua agressividade. Corroborando com a pesquisa de Paixão et al. (2018), ao mencionar que as situações de risco que os jovens vivenciam no ambiente familiar como: negligência, violência física, psicológica e sexual, rigidez nas práticas educativas, bem como supervisão inadequada podem desencadear transtornos disruptivos e agressividade. Nesse mesmo contexto, a Organização Mundial da Saúde (OMS) (2002) indica que fatores como a impulsividade, atitudes ou crenças agressivas, resultado escolar ruim, influência da mídia e locais com altos índices de criminalidade e pobreza podem contribuir para a violência dos jovens.

Quanto às características dos autores e alvos da agressão, presentes na tabela 5, ficou em evidência que, para os alunos, os praticantes da violência são os mais populares e fortes, enquanto as vítimas são pessoas impopulares e fracas. Esses dados confirmam a teoria de Leon e Nicole Crochick (2017a), na qual os praticantes seriam alunos com maior desempenho na hierarquia não oficial, nesse caso, a popularidade e força; e as vítimas seriam piores em ambas as hierarquias. Para esses autores, a fragilidade dos sujeitos passa a suscitar o desejo da dominação por parte dos agressores. Nota-se que existe um uso da força para coagir e agredir indivíduos que não estão em posição de defesa. Além disso, Crochík et al. (2014) apontam que a cessação da violência não depende da vítima, “(...) a não ser que ela se iguale na força, o que não resolve o problema, só o reproduz" (p. 117).

O fenômeno da violência escolar, sendo visto de forma mais ampla, é muito mais complexo do que podemos perceber. Esses atos de agressividade podem ter relação com a comunidade e vivências dos alunos, a família, com a competição que é largamente estimulada em nossa sociedade, com o desejo de dominação, os preconceitos, normalização da violência, bem como com a falta de afeto.

Contudo, como já mencionamos anteriormente, a escola e seus sujeitos fazem parte da nossa sociedade e acabam por reproduzir um modelo centrado na acumulação de bens e na valorização de relações competitivas e de dominação. Mas pensamos que é possível uma educação emancipadora e que valorize as relações harmônicas entre os indivíduos, para que a nossa prática diária possa se voltar para a "desbarbarização" dos sujeitos. 
Adorno (1995, p.127), em seu texto “Educação após Auschwitz”, menciona a importância de se analisar a ambiguidade da função do esporte: “(...) pode ter um efeito contrário à barbárie e ao sadismo, (...) Por outro, em algumas de suas modalidades e procedimentos, ele pode promover a agressão, a brutalidade e o sadismo" Sendo assim, é importante pensar em práticas educativas esportivas (ou não) que valorizem o trabalho coletivo, dialógico e de respeito ao próximo. Para ele, “(...) quem é severo consigo mesmo adquire o direito de ser severo também com os outros, vingando-se da dor cujas manifestações precisou ocultar ou reprimir” (p. 128).

\section{Considerações finais}

Devemos refletir diariamente sobre qual o tipo de educação queremos fornecer aos nossos alunos e, a partir disso, pensarmos em medidas formativas do ponto de vista acadêmico, mas também sobre as relações de convivência e respeito entre todos os sujeitos: “(...) Os interesses e necessidades dos outros devem ser considerados como próprios, sem que se negue os próprios interesses e necessidades, que deverão também ser defendidos pelos demais" (CROCHICK; CROCHICK, 2017a, p. 27). Logo, é necessário repensar essas práticas no ambiente escolar, de forma a amenizar os efeitos das hierarquias já mencionadas, ou seja, do desejo de dominação e de violência entre os indivíduos.

Medidas educacionais devem ser voltadas para a valorização do coletivo, da solidariedade, do respeito às diferenças e não apenas se apresentarem como medidas punitivas que excluam e coloquem o sujeito como apenas o único responsável pelos seus atos, analisando e pensando, desta forma, esse sujeito, dentro do seu contexto e da sua realidade. A partir dessa compreensão é importante pensarmos em medidas que envolvam a família, a comunidade, a mídia, os sistemas de saúde, as políticas e também o sistema educacional.

\section{Referências}

ADORNO, T., et al. Teoria da Cultura de Massa. Introdução, Comentários e Seleção de Luiz Costa Lima. Rio de Janeiro: Paz e Terra, 1986.

CORRÊEA, A.S. (In)disciplina e Bullying nas práticas escolares de diretores, coordenadores, docentes e alunos: uma análise à luz da Teoria Crítica. Tese (Doutorado - Programa de Pós-Graduação em Psicologia Escolar e do Desenvolvimento Humano) Instituto de Psicologia, Universidade de São Paulo, 2017.

CROCHICK, J. L, et al. Análise de concepções e propostas de gestores escolares sobre o Bullying. Acta Scientiarum Education, v. 36, n. 1, p. 115-127, Jan.-June, 2014.

CROCHICK, J. L. \& CROCHICK, N. Bullying, preconceito e desempenho escolar: uma nova perspectiva. São Paulo: Benjamin Editorial, p. 120, 2017 a. 
DA SILVA, J.L.; DE OLIVEIRA, W.A.; DE MELLO, F.C.M. et al. Revisão sistemática da literatura sobre intervenções antibullying em escolas. Ciência \& Saúde Coletiva, 22(7): 2329-2340, 2017. https://doi.org/10.1590/1413-81232017227.16242015.

DE ALCANTARA, S.C.; GONZÁLEZ-CARRASCO, M.; MONTSERRAT, C. et al. Violência entre pares, clima escolar e contextos de desenvolvimento: suas implicações no bem-estar. Ciência \& Saúde Coletiva, 24(2): 509-522, 2019. https:/ / doi.org/10.1590/1413-81232018242.01302017.

DE OLIVEIRA, W.A.; DA SILVA, J.L.; BRAGA, I.F. et al. Modos de explicar o bullying: análise dimensional das concepções de adolescentes. Ciência \& Saúde Coletiva, 23(3): 751-761, 2018. https://doi.org/10.1590/1413-81232018233.10092016.

DE OLIVEIRA, W.A.; DA SILVA, J.L.; SAMPAIO, J.M.C. et al. Saúde do escolar: uma revisão integrativa sobre família e bullying. Ciência \& Saúde Coletiva, 22(5): 1553-1564, 2017. https://doi.org/10.1590/1413-81232017225.09802015.

GIORDANO, R.C. \& NAZARETH, L.J.S. Violência, educação e sociedade: o bullying na concepção de educadores em Ananindeua (PA). Comunicações Piracicaba, v. 24, n. 2, p. 103-126, 2017. https://doi.org/10.15600/2238-121X/comunicações.v24n2p103-126.

KRUG, EG.; DAHLBER, LL.; MERCY, JA.; ZWI, AB.; LOZANO, R. World reportonviolence and health. Geneva: World Health Organization; 2002.

MALTA, D.C.; BERNAL, R.T.I.; PUGEDO, F.S.F. et al. Violências contra adolescentes nas capitais brasileiras, segundo inquérito em serviços de urgência. Ciência \& Saúde Coletiva, 22(9): 2899-2908, 2017. https://doi.org/10.1590/1413-81232017229.14212017.

MONTEIRO, T.A. \& SARAVALLI, E.G. (2015). Crenças sobre violência: um estudo brasileiro a partir do referencial piagetiano. Avances em Psicología Latinoamericana, 33(2), 189-201. dx.doi.org/10.12804/apl33.02.2015.02.

NETO, A. A. L. Bullying - comportamento agressivo entre estudantes. Jornal de Pediatria, 81, S164- S172, 2005. https://doi.org/10.1590/S0021-75572005000700006.

OLIVEIRA, J.C. \& BARBOSA, A.J.G. Bullying entre Estudantes com e sem Características de Dotação e Talento. Psicologia: Reflexão e Crítica, 25(4), 747-755, 2012.

https://doi.org/10.1590/S0102-79722012000400014.

PAIXÃO, R.F.; PATIAS, N.D. \& DELL'AGLIO, D.D. Relações entre Violência, Clima Familiar e Transtornos Mentais na Adolescência. Revista Interinstitucional de Psicologia, 11(1), 2018, 109 -

122. http://dx.doi.org/10.36298/gerais2019110109.

SILVA, J. M. A. P.; SALLES, L. M. F. A violência na escola: abordagens teóricas e propostas de prevenção. Educar em Revista, Curitiba, Brasil, n. especial 2, p. 217-232, 2010. https://doi.org/10.1590/S0104-40602010000500013.

SILVA, B.R.V.S.; DA SILVA, A.O.; DOS PASSOS, M.H.P. et al. Autopercepção negativa de saúde associada à violência escolar em adolescentes. Ciência \& Saúde Coletiva, 23(9): 2909-2916, 2018. https://doi.org/10.1590/1413-81232018239.12962018. 